\title{
Tackling bullying and harassment in the
}

NHS: the critical roles played by

\section{managers}

\section{Lewis, DO}

http://hdl.handle.net/10026.1/13116

\subsection{8/bjhc.2019.25.1.7}

British Journal of Healthcare Management

Mark Allen Healthcare

All content in PEARL is protected by copyright law. Author manuscripts are made available in accordance with publisher policies. Please cite only the published version using the details provided on the item record or document. In the absence of an open licence (e.g. Creative Commons), permissions for further reuse of content should be sought from the publisher or author. 


\title{
Tackling Bullying and Harassment in the NHS: The Critical Roles Played by
}

\section{Managers}

Duncan Lewis \& Roger Kline

\section{Duncan Lewis}

Professor of Management, Plymouth Business School \& Adjunct Professor, School of Business \& Law, Edith Cowan University, Perth, Australia

Roger Kline

Research Fellow, Middlesex Business School

Email: Duncan.Lewis@plymouth.ac.uk

\begin{abstract}
This article outlines some of the key insights gained from 30 years of personal involvement with NHS Trusts in tackling bullying and harassment. It seems more pertinent than ever to raise the critical importance played by managers in stopping this most malevolent of issues. Failing to do so will foreshadow even greater problems for managers, leaders, the wider NHS workforce and ultimately patients. We begin with some case illustrations gathered from our work in different NHS Trusts. These illustrate why managers need to be attuned to some of the underlying causes as to why bullying and harassment flourishes in the NHS.
\end{abstract}


Keywords: Bullying, Harassment, Management, Leadership, Workplace Conflict

\section{Some cases in point}

In maternity Julie sips her cup of tea alone. Her colleagues make tea for each other but never ask Julie if she would like a cuppa. She feels lonely and isolated but can't leave because her partner's job keeps them in the locality. Over in Emergency, Billy is new - in week 8 of his job. Billy is an admin assistant on an apprenticeship pathway and his manager says: "Alice isn't in today, so I want you take over the reception desk". Billy explains that he hasn't done this before but his manager shouts “We don't have time to talk about it, just get out there now!". Colleagues look at Billy but say nothing. Six weeks later Billy resigns. Jonathan is a Consultant and has worked in the NHS for over 25 years doing a job he loves. However, the behaviours towards him from one or two of his fellow consultants leave him feeling demeaned and with thoughts of suicide, something he later attempts. Their undermining of his competence, questioning of his commitment and constant attempts at side-lining him in favour of a junior, less experienced doctor, lead him to quit. Out on the road, paramedic Sue is 10 hours into her 12 -hour shift. She is praying that her shift ends on time as she has promised her twins she will be there for their big performance in the school play; then the call comes for an urgent patient transfer to a specialist hospital two hours away. This will be her $12^{\text {th }}$ over-run out of 14 shifts and she knows if this continues her relationship with her family will be in jeopardy. Three months later Sue leaves for a job in a GP practice. 


\section{Understanding Bullying \& Harassment}

Readers may interpret that these four illustrations, taken from real interviews with NHS staff, hardly constitute the typical portrayal of a bullying scenario. But what is bullying and harassment? Why are these issues such a problem in the NHS? Who is at fault and what can we do about them? A starting point is the question used in the annual survey to NHS staff which states, 'In the last 12 months have you personally experienced harassment, bullying or abuse at work from' and includes three response possibilities: a) patients/service users, their relatives or members of the public; b) managers; or c) other colleagues. Immediately the respondent to the survey has to interpret for themselves what bullying, harassment and abuse mean and, having done so, respond accordingly. Some months later, the individual NHS organisation obtains their institution's results and finds 25\% (typically) reporting bullying or harassment (NHS, 2017 staff survey). But which is it? Bullying? Harassment? Abuse? Or all three? Equally important is that the organisation has no idea what lies behind their results. What it does know is that $13 \%$ emanate from managers, $18 \%$ from co-workers and $28 \%$ by patients/their relatives (2017 NHS Staff Survey). This locates the result clearly as a manager problem, regardless of perpetrator. Research shows that when survey respondents are given a definition of bullying, incidence rates on average fall by around $7 \%$ compared to studies where no definition is given (Nielsen, et al. 2010).

Bullying is best understood as repeated negative behaviour where the individual recipient neither wants what is happening to them, nor is able to defend themselves from it. Bullying causes distress, offence and humiliation (Einarsen, et al. 2011). Each NHS organisation will have its own policy on bullying and harassment and most will follow best practice guidelines 
aligned typically to definitions provided by organisations like Acas. In our experience, bullying policies can be lengthy, complex and difficult to follow and for some staff, offputting simply by having to digest and understand them. Take for example the case of Billy above. Would a young apprentice be confident to access, interpret and deploy the actions expected of a policy? Unlikely. Would Julie risk her job by exploring the policy to see if it covers feeling isolated and left out of the tea break round? Also, unlikely. As such, policy has its place (see Rayner and Lewis, 2011) but it is one tool in the armoury for tackling bullying. Similarly, our experience shows that many NHS Trusts favour a process of grievance raising by staff (generally as individuals) who may feel bullied. This is not helpful for the majority of staff who are simply unable to affect a grievance, particularly if this is against a manager or a senior medical colleague, because of the potential consequences of doing so.

A major problem facing NHS organisations is understanding the behaviours that lie behind bullying and harassment (BMA, 2018). Previous research has shown that health and social care as a work sector suffers from a spectrum of 21 inappropriate behaviours classified into 3 sub-groups: unreasonable management pressures; incivility and disrespect behaviours and violence/injury (Fevre, et al., 2012). Globally, nursing (and midwifery) has been shown to be dogged by bullying (Blackwood, et al., 2017; Hartin et al., 2018) but bullying is also prevalent amongst doctors (Quine, 2002; BMA, 2018) and dentists (Steadman et al., 2009). As previously reported, most parts of the NHS system are affected by bullying (Illing, et al. 2013) and recent estimates have conservatively costed bullying and harassment at $£ 2.28$ Billion per annum (Kline and Lewis, 2018). 


\section{So, what must managers do?}

A starting point for managers is to recognise that conflict is an everyday occurrence in all organisations and that bullying affects organisations of all sizes (Lewis et al., 2017) but is more prevalent as organisations get bigger and more complex (Fevre, Lewis, Robinson and Jones, 2012). Fevre et al. (2012) showed that most unreasonable treatment was attributed to managers with a lesser amount attributed to work colleagues, whereas most incivility and disrespect was equally distributed between managers and colleagues as perpetrators. Given that we know $13 \%$ of bullying in 2017 in the NHS was attributed to managers, a starting point has to be a manager's own behaviours. Inappropriate manager behaviours can be a product of a stressful work environment where poor role clarity for employees, excessive job demands, poor management/communication around change, insufficient resources to undertake the work tasks and a lack of autonomy to get on with a job role can all contribute to feelings of bullying and/or harassment (Illing et al., 2013; Lewis, et al., 2017). Such stressful work environments are often characterised by micro-management, autocratic management styles and poor emotional intelligence by managers in spotting that things are not as they should be. A good manager would be looking at Sue, our paramedic example, and recognising the negative impacts of over-runs on her and the unsustainable nature of such expectations. If we remember that bullying is a repeated and escalating process, it follows that early intervention by managers is crucial so that relatively simple acts of incivility, such as the failure to include Julie in the tea-round, are addressed quickly. Similarly, shouting at Billy in front of colleagues and expecting him to fulfil a task for which he is unprepared, demonstrates problems of role clarity, poor communication and insufficient knowledge for Billy to execute the role. 
A lack of manager support has been cited as a key stressor in British workplaces (HSE, 2017). Managers must therefore make time to explain actions, offer support to those executing them and ensure clarity of communication. This all takes time, and in the pressured environments of the NHS this may seem a luxury that managers can ill-afford. Yet we know that managers who do recognise the value in engaging their teams and being supportive reap dividends. In contrast, managers who execute laissez-faire leadership styles (Skogstad et al., 2007) by not intervening when they should or, through hoping events sort themselves out, create an image of irrational behaviour that employees simply do not understand (Fevre et al., 2012). Ignoring conflicts or hoping they go away does not work. Employees expect to be managed but presume this will be fair and transparent. All too often we hear in interviews with NHS staff that managers do not, for example, distribute leave/shifts/access to training fairly. It is essential that fairness and transparency lie at the heart of manager decision-making.

Managers must also be aware of the cultural dynamics in operation amongst their teams and between them and their teams. If incivility and disrespect is allowed to flourish unchecked, it provides a fertile environment for relatively minor acts to develop into fullblown bullying. Whilst some issues may appear initially to be indiscriminate or irregular, it is a manager's responsibility to act swiftly and decisively so that matters cannot escalate. It is clearly in a manager's, let alone employee's, interest to do so, given that sickness absence, diminished productivity, employees leaving to seek other posts, as well as costs associated with grievances, employment tribunals and litigation are direct outcomes of bullying (Kline and Lewis, 2018). Buchan et al. (2017) estimated that 84,000 nurses will leave before retirement age and when combined with vacancies of 29,000 (Health Education England 
2016/2017), engagement with staff to maximise retention and commitment to the NHS has never been greater. Managerial intervention is absolutely key to tackle bullying and harassment and reducing turnover. Yet, this requires skills and competencies not always inherent in those executing managerial roles; just because someone is a good clinician or administrator, it cannot be assumed that they will make a good manager.

NHS organisations must re-double their efforts to ensure they have the right managers with the right competencies and then actively support inexperienced managers by means of manager networks. This could include mentors/buddies, anonymous blogs/posted questions seeking advice, as well as more formal training in conflict management and resolution. Whilst mediation has its place in reducing conflict (Latreille and Saundry, 2015), it is not a one-size-fits-all solution. Bullying, by definition, is a repeated and escalating process. To expect someone such as Jonathan (in our example above) to sit down and mediate with colleagues that have persistently and consistently demeaned him publicly, is neither moral nor sensible and could do more harm than good. A key manager attribute is knowing which tool to deploy when.

Most targets of bullying simply want the behaviours they encounter to stop and for work to be normal and civil once again. Whilst much work has been done to improve the voice channels available to staff, partially resulting from the reports by Sir Robert Francis in 2013 and 2015 , too many staff, including doctors (BMA, 2018) are fearful to speak up. However, if staff are encouraged to speak up, organisations must act and be seen to both respond to the concerns raised and protect the persons raising them. If organisations do not know of problems because staff will not speak up, problems cannot be addressed. Most Freedom to 
Speak Up Guardians (FSUG) are undertaking this role alongside another. Some are more effective than others. If we want people to speak up, FSUG's need to take a more proactive role rather than waiting for contact to be made. Opening a helpline for staff in isolation is not enough. Effective strategies to change the 'organisational climate' require the commitment of line managers with leadership from HR in being proactive and preventative rather than just responding to individual complaints. Finally, and crucially, the tone of the organisation is set from the Board and senior managers who lead it and staff notice the behaviours which seem to act as potential markers on how to progress careers.

\section{Conclusions}

Leading and managing by example only works when leaders and managers have the wherewithal to understand their own behaviours or are willing to be questioned if such behaviours misalign with norms. Epictetus told us two millennia ago about the value of having two ears and one mouth. Managers and leaders both in and outside of NHS organisations would do well to remember the value of listening more and speaking less.

\section{References}

Blackwood K, Bentley T, Catley B, Edwards M. (2017). Managing workplace bullying experiences in nursing: the impact of the work environment. Public Money and Management, 37(5): 349-356.

Bullying and harassment: how to address it and create a supportive and inclusive culture. British Medical Association (2018). 
Buchan J. et al. (2017). Rising Pressure: The NHS Workforce Challenge (Health Foundation).

Einarsen S, Hoel H, Zapf D, Cooper CL. (2011). The Concept of Bullying and Harassment at Work: The European Tradition. In: S. Einarsen, H. Hoel, D. Zapf, \& C.L. Cooper (Eds.) Bullying and Harassment in the Workplace: Developments in Theory Research and Practice (pp.3-39). London: CRC Press.

Fevre R, Lewis D, Robinson A, Jones T. (2012). Trouble at Work. London: Bloomsbury Academic Press.

Francis R. (2013). Report of the Mid Staffordshire NHS Foundation Trust Public Inquiry (TSO).

Francis R. (2015). Freedom to Speak Up: An Independent Review into Creating an Open and Honest Reporting Culture in the NHS.

Hartin P, Birks M, Lindsay D. Bullying and the nursing profession in Australia: An integrativereview of the literature. Collegian (2018), https://doi.org/10.1016/i.colegn.2018.06.004

Health Education England (HEE) (2016/2017). Workforce Plan for England (https://hee.nhs.uk).

HSE (2017). Work-related Stress, Depression or Anxiety Statistics in Great Britain 2017. London: Health and Safety Executive. 
Iling JC, Carter M, Thompson NJ, Crampton PES, Morrow GM, Howse JH, Cooke A, Burford BC. (2013). Evidence synthesis on the occurrence, causes, consequences, prevention and management of bullying and harassing behaviours to inform decision making in the NHS. National Institute for Health Research, Southampton, UK.

Kline R, Lewis D. (2018). The price of fear: estimating the financial cost of bullying and harassment to the NHS in England. Public Money and Management.

\section{http://dx.doi.org/10.1080/09540962.2018.1535044.}

Latrielle P, Saundry R. (2015). Towards a system of conflict management? An evaluation of the impact of workplace mediation at Northumbria Healthcare NHS Foundation Trust. London: Acas.

Lewis D, Megicks P, Jones P. (2016). Bullying and harassment and work-related stressors: Evidence from British small and medium enterprises. International Small Business Journal, 35(1): 116-137.

NHS England (2017), See www.nhsstaffsurveys.com/Page/1064/Latest-Results/2017-Results

Nielsen MB, Matthiesen SB, Einarsen S. (2010). The impact of methodological moderators on prevalence rates of workplace bullying. A meta-analysis. Journal of Occupational and Organizational Psychology, 83, 955-979. 
Quine L. (2002). Workplace bullying in junior doctors: questionnaire survey, British Medical Journal, 324: 878-879.

Rayner C, Lewis D. (2011). Managing Workplace Bullying: The Role of Policies. In: S. Einarsen, H. Hoel, D. Zapf, \& C.L. Cooper (Eds.) Bullying and Harassment in the Workplace: Developments in Theory Research and Practice (pp.327-339). London: CRC Press.

Skogstad A, Einarsen S, Torsheim T, Aasland MS, Hetland H. (2007). The Destructiveness of Laissez-Faire Leadership Behaviour. Journal of Occupational Health Psychology, 12, 80-92.

Steadman L, Quine L, Jack K, Felix D, Waumsley J. (2009). Experience of workplace bullying behaviours in postgraduate hospital dentists: Questionnaire study. British Dental Journal, 207: 379-380. 